\title{
The sports hernia: a cause of chronic groin pain
}

\author{
Roger G. Hackney FRCS, Dip Sports Med \\ Princess Mary's Hospital, Royal Air Force Halton, Aylesbury, Bucks, UK
}

\begin{abstract}
The management of chronic pain in sportsmen and women requires consideration of a wide differential diagnosis. A syndrome caused by a distension of the posterior inguinal wall is described, effectively an early direct inguinal hernia. The diagnosis can be made from certain aspects of the history and examination, which are described. The results of surgical repair to the posterior inguinal wall are excellent. The procedure was carried out on 14 sportsmen and one woman. There is an $87 \%$ return to full sporting activity, with a follow-up of 18 months to 5 years. The remaining $13 \%$ were improved by the repair. Many of the athletes had received other treatments without success. The sports hernia should be high on the list of differential diagnoses in chronic groin pain.
\end{abstract}

Keywords: Groin pain, inguinal hernia

Chronic groin pain in sportsmen and women is a complex diagnostic and therapeutic problem. Groin injuries account for only $5 \%$ of those attending a sports injury clinic ${ }^{2-3}$ but are responsible for a much larger proportion of time lost from competition and work $^{4}$. Many different syndromes have been described and aetiologies postulated ${ }^{5-7}$, but the syndrome of a weakness of the posterior inguinal wall without a clinically recognizable hernia causing chronic groin pain has not been widely appreciated. The differential diagnosis includes orthopaedic, urological, general surgical, and gynaecological causes of pain. The chronic groin pain of sportsmen is often diffuse; the symptoms may progress to affect daily life. The presentation is varied; the diagnosis can be made from the history and examination. The condition does not respond well to conservative measures including prolonged rest, with perhaps only $20 \%$ returning to full activity. The syndrome can be treated surgically with excellent results. The results of surgery to the inguinal region are presented.

\section{Materials and methods}

There were 15 patients, including only one woman, with an age range of 18 to 38 years. All were active in competitive sports, or involved in strenuous physical exercise in the armed services. The average duration of symptoms to operation was 20 months (range of 6

Address for correspondence: Sdn Ldr R. G. Hackney, Department of Orthopaedics and Trauma, University Hospital, Queens Medical Centre, Nottingham, UK

(C) 1993 Butterworth-Heinemann Ltd 0306-3674/93/010058-05

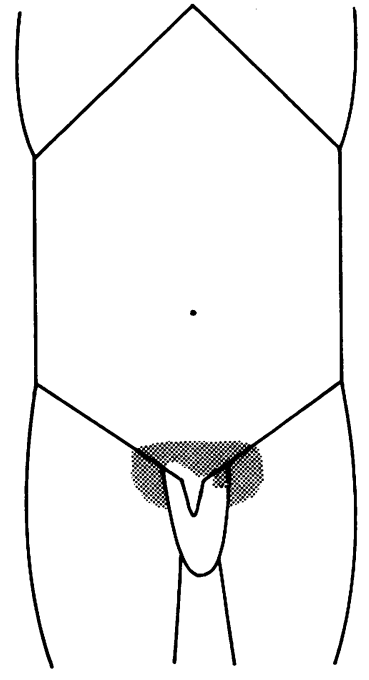

Please shade the areas where you felt pain prior to your operation

Figure 1. Diagram to enable patient to identify areas where pain was felt

weeks to 5 years). The indication for operation was groin pain thought to be caused by a weak posterior inguinal wall.

A mixture of a postal survey and clinical outpatient follow-up was used to assess the results. Patients were asked to shade the areas where pain was felt before operation on the diagram shown in Figure 1, to assess the variability of the site of pain. An analogue pain scale was also completed to express the severity of the pain.

\section{Diagnosis}

\section{History}

The groin pain may be of an insidious onset, or result from a sudden tearing sensation. Runners tend to give the former history, contact sportsmen either. It is of note, however, that a footballer will report that although he has had 'groin strains', by which he means adductor muscle pulls, in the past, this new injury is felt 'deeper' and more strongly. The pain often does not trouble the athlete during competition in the early stages, but gives rise to aching during the following evening. As he continues to train, the discomfort begins to appear towards the end of a game or run. As the problem progresses, the pain comes on earlier and is more severe, such that it is impossible to stride out or turn quickly without a stab of pain. The pain diagrams show the areas to which 


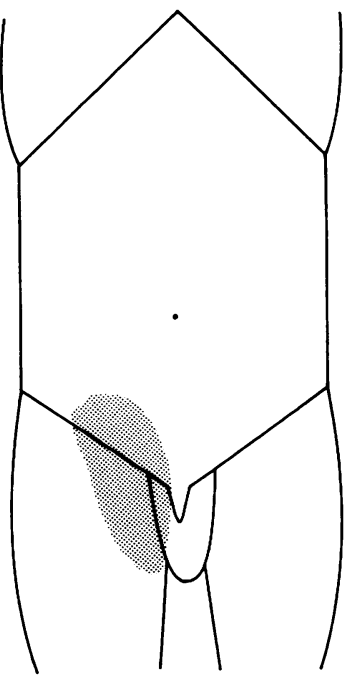

Patient 4

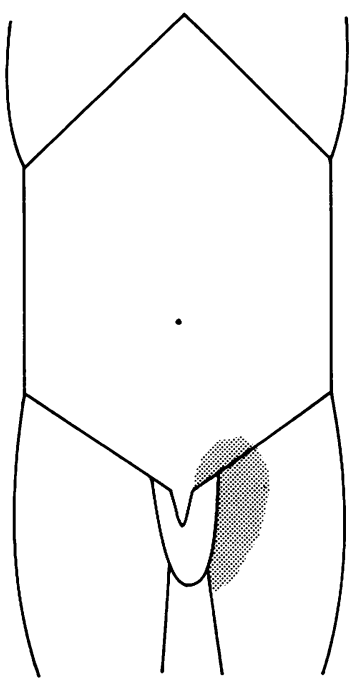

Patient 14

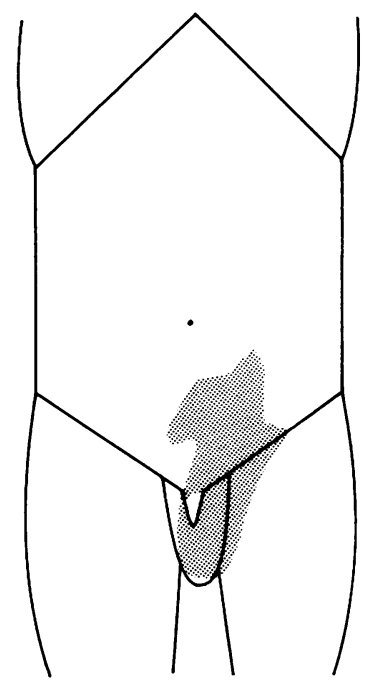

Patient 15

Figure 2. Pain diagrams for patients 4,14 and 15 . Each diagram is accompanied by the following instruction: 'please shade the areas where you felt pain prior to your operation'

the pain spreads (Figure 2). Typically, it is worse on one side, but radiates laterally and across the midline, down the inside of the thigh into the adductor area, into the scrotum and testicle - and can cause pain on sexual intercourse. Some patients complain of pain in the perineum and up into the abdomen. The pain in the scrotum can be a prominent feature and lead to investigation for testicular abnormality. Four patients underwent ultrasonographic examination, and two were undergoing surgery to their testicles before referral. The groin pain becomes severe; it becomes impossible to run, play or train, and help is sought. In these first 15 patients undergoing surgery, a history of pain on coughing was not always asked for. In a later unreported series just over half of the respondents gave a history of pain on coughing. Gilmore $^{8}$ regards this history as important, but my experience is that it is present only in those with a longer, more obvious history.

\section{Examination}

The findings on examination are dependent upon how much rest and intercurrent treatment the sportsman has received. Many patients had already undergone prolonged periods of physiotherapy before referral and lengthy spells of rest. The pain disappears on prolonged rest, only to recur with the same intensity on resuming training. The best time to perform the examination is after a return to exercise and a return of the pain. Indeed, this history itself is a good guide to identifying the syndrome. When the athlete has tried to 'run' through the pain, virtually the whole of the groin area is extremely painful.

Adductor stretch is usually painful with tenderness around the belly and origin of the group, but the patient will recognize that the tenderness palpated is not the source of the pain. The symphysis pubis is tender. The pain is worse over the pubic tubercle of the affected side. The scrotum is then invaginated and the inguinal rings palpated from the inside. The area around the external ring is tender. When the mid-inguinal canal is palpated, the patient usually confirms that the pain is both worst there and is aggravated by coughing. A slight cough impulse can be felt in some cases, but its significance is debated. The testes are formally examined to exclude local pathology.

\section{Special investigations}

Initially, patients were considered for operation on the history and examination findings alone. Recently, patients have been investigated with a herniogram, later modified to include a computed tomographic herniogram. The objective is to attempt to provide an accurate diagnostic test, but also by injecting local anaesthetic with the dye, to attempt to discover the source of pain. Preliminary findings have been reported elsewhere ${ }^{9}$. The appearances, when positive, appear to show a distension of the peritoneal folds, indicating a general stretching out of normal fascial layers. Ekberg et al. ${ }^{10}$ used herniography to investigate chronic groin pain, but did not operate on those with negative findings.

\section{Operative technique and findings}

A standard parainguinal approach was used, and the external oblique muscle incised in the line of its fibres opening the external inguinal ring. The spermatic cord was raised and the internal inguinal ring inspected for an indirect hernial sac and the competence of the ring. The transversalis fascia and conjoined tendon were carefully assessed. The repair, which extended to reconstitute the internal ring, was performed with plication of transversalis fascia. The plication was then covered by a darn of 
non-absorbable suture apposing the conjoined tendon to the inguinal ligament.

The findings at operation are to some extent dependent upon the duration of symptoms. The abnormalities becoming more obvious with time. In all cases there was seen to be a weakening of the transversalis fascia with separation from the conjoined tendon. In the case of Patient 14 (Figure 2) who was unable to walk without pain before operation, the weakness amounted to a direct hernia. The internal ring is dilated and often with the inferior epigastric vessels clearly visible. In no case was there more than a small knuckle of peritoneum seen at the internal ring. With a short duration of symptoms the defect seems to be more to the medial end of the inguinal canal. The early appearances found in a well-muscled sportsman consisted of a palpable defect once the spermatic cord was lifted and weakness between the otherwise substantial transversalis fascia and the conjoined tendon.

\section{Return to sport}

Postoperatively, there is a gradual return to training with stretching and non-weight-bearing exercise such as swimming or cycling after 3 weeks. Running commences at 4-5 weeks, with daily training at 6 weeks. Many experienced slight pulling in the groin during this period, but this settled.

\section{Results}

The results of the surgery to the inguinal region are presented in the first 15 sportsmen and woman (Table 1 ). Since surgery several of the runners have gone back to winning races. One has returned to have the second side repaired, and since this series began, two more from a case-load of 45 have required repair of the second side, recognizing the symptoms themselves.

Of the two who did not have an excellent result, one (Patient 11) was able to return to playing football and run $16.1 \mathrm{~km}$, but was still unable to sprint as fast as he wished, and had pain which prevented him completing a training session. Both went on to have adductor tenotomy within the Armed Service system and were further improved following this, such that they were optimistic about returning to full sport.

The pain distribution diagrams (Figure 2) showed a wide variability in the areas shaded. All patients shaded the area over the inguinal canal and adductor origin. Some had referred pain into their scrotum, inner thigh, proximally in the midline, or laterally along the inguinal ligament.

\section{Discussion}

There have been a few reports of similar procedures for chronic groin pain in sportsmen in the literature, with much anecdotal reporting of international footballers returning to complete fitness after groin surgery.

Our patients achieved better than $80 \%$ return to full activity after failure of all conservative means. The minimum follow-up is 18 months, the longest over 5 years. Patients 4,5 and 13 in particular had been seen by several doctors of a wide range of specialities, had received the whole range of conservative measures, including many physiotherapeutic modalities and local anaesthetic and steroid injections with no lasting relief.

It has been argued that the improvement is due to a 'proper' rest after such surgery. However, two of the patients in this series, Patients 11 and 15, had undergone testicular fixation and epididymectomy respectively for the testicular component of their pain, without any relief of symptoms whatsoever, either immediately after operation or after the enforced rest.

Palpable hernias are irregularly reported as causing chronic groin pain ${ }^{11}$. Taylor et al. ${ }^{12}$ describe nine cases, two of whom they stated had no evidence of hernia before operation. The site of maximal tenderness, painful cough impulse, and operative findings all suggest that a distension of the posterior inguinal canal wall musculature, an early type of direct hernia,

Table 1.

\begin{tabular}{|c|c|c|c|c|c|c|c|c|}
\hline $\begin{array}{l}\text { Patient } \\
\text { no. }\end{array}$ & Duration & $\begin{array}{c}\text { Operation } \\
\text { date }\end{array}$ & Sport & Level & $\begin{array}{l}\text { Previous } \\
\text { Treatment }\end{array}$ & $\begin{array}{l}\text { Pain } \\
\text { scale }\end{array}$ & Competition & $\begin{array}{c}\% \\
\text { Success }\end{array}$ \\
\hline 1 & $6 / 52$ & February 1987 & Football & Club & Rest & 7 & Full & 100 \\
\hline 2 & $10 / 12$ & March 1988 & Netball & County & Adductor tenotomy & 6 & Full & 100 \\
\hline 3 & $18 / 12$ & July 1988 & Football & Club & Physiotherapy & 8 & No & $*$ \\
\hline 4 & 2 years & October 1988 & Running & Olympic & Steroid injection & 8 & Full & 100 \\
\hline 5 & 5 years & March 1989 & Running & Country & MUANNSAID & 6 & Full & 100 \\
\hline 7 & $6 / 12$ & May 1989 & Rugby & Corps & Rest/NSAID & 9 & Full & 100 \\
\hline 8 & $18 / 12$ & May 1989 & Rugby & County & Self treatment & 8 & Full & 100 \\
\hline 9 & $21 / 12$ & August 1989 & Rugby & Div 2 & Steroid injection & $7-8$ & Full & 100 \\
\hline 10 & 4 years & September 1989 & Squash & Club & Physiotherapy & 7 & Full & 100 \\
\hline 11 & 2 years & October 1989 & Football & Station & Operation & 8 & Reduced & $30^{*}$ \\
\hline 12 & $9 / 12$ & October 1989 & Football & Club & Rest & 4 & Knee & $100 t$ \\
\hline 13 & $8 / 12$ & October 1989 & Sprints & Country & Steroid injection & 5 & Full & 100 \\
\hline 14 & $5 / 12$ & February 1990 & Football & Station & Physiotherapy & 7 & Full & 100 \\
\hline
\end{tabular}

* Patients 3 and 11 have since received adductor tenotomy and Patient 11 is now able to run $8 \mathrm{~km}$ and play matches + Knee injury on return to competition

MUA, manipulation under anaesthetic; NSAID, non-steroidal inflammatory drug; 
is the likely explanation. We have called this syndrome a sports hernia.

The particular problems are the variability in distribution of the pain and the precise local pathology. The pain diagrams (Figure 2) illustrate this variability. The conclusion is that the site of pain cannot be relied upon in the diagnosis of this condition. Ekberg et al. ${ }^{10}$ reported nerve entrapment in this region as the cause of groin pain ${ }^{13,14}$.

Other authors also use a standard hernia repair to achieve success. Smodlaka ${ }^{15}$ reports that Nessovic in Yugoslavia uses a Bassini repair with success. Horsky and Huraj ${ }^{16}$ report strengthening of the inguinal ligament and transversalis fascia to be effective. Hess $^{17}$ and Hess and Huberty ${ }^{18}$ refer to the open inguinal ring, where the peritoneum moves into the gap between the 'internal muscle and the inguinal ligament'. They sometimes found oedema of the spermatic cord. The type of surgery performed is not described, but they state that no conservative measures succeed. Schneider ${ }^{19}$ performs a closure of the external ring and a doubling of external aponeurosis and subcutaneous placement of the spermatic cord. He considers the site of the problem to be an insufficiency of the external ring and aponeurosis. Hyde (personal communication) calls the syndrome chronic conjoint tendon syndrome and denies any herniation, believing the problem to be more medial. He reattaches the insertion of the conjoined tendon, emphasizing the tightening of the tendon. He claims a $90 \%$ success rate over 6-8 weeks with over 500 operations performed, but without publishing results. Martens ${ }^{20}$ differentiated the syndrome into three types, depending upon the predominant site of pain. He operates upon the origins of the adductor group, insertion of rectus abdominis, or the posterior inguinal canal, but did not present figures or results.

There appears to be a relationship between this syndrome and osteitis pubis with some overlap of symptoms. Cochrane ${ }^{21}$ gives a detailed account of the progression of symptoms in two footballers. Harris and Murray ${ }^{22}$ found that the more athletic the person, the greater the incidence of osteitis pubis. The radiological appearances of osteitis pubis are common in footballers with a reported incidence as high as $14-28 \%{ }^{15}$. Harris and Murray ${ }^{22}$ also stated that the radiographic appearances lagged behind the clinical picture and remained after the symptoms settled. Le Jeune et al. ${ }^{23}$ investigated 32 cases of pubic pain with scintigraphy using technetium $99 \mathrm{~m}$ and reported a closer relationship with the clinical course when the scan was positive, but did not give the clinical history for his cases. Hanson et al. ${ }^{24}$ stated that set-backs in treating osteitis pubis are common and frustrating. Gullmo ${ }^{25}$ recommended herniography for those with chronic groin pain and osteitis pubis, as he noted a correlation. The success rate (return to full sport) for treating osteitis pubis is reported to be as low as $20 \%$. It is not thought that the condition of sports hernia and osteitis pubis are identical, but rather that they are closely linked, perhaps with the same aetiology.

Theories of aetiology of the condition of chronic groin pain due to stretching and tearing of transversalis and conjoint tendon have been described. The

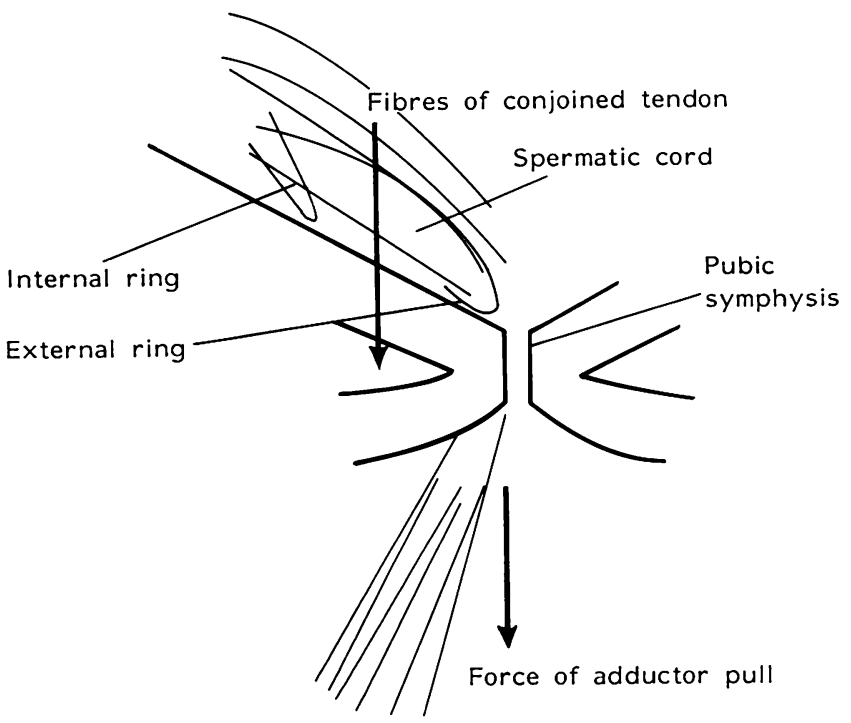

Figure 3. Diagram illustrating the possible cause of sports hernia

first implicates a reduction in internal rotation of the hip joint. Inward twisting then produces a shearing force across the pubic symphysis from adductor pull $^{26,27}$. This leads to stress on the inguinal wall musculature perpendicular to the lie of the fascia and muscle fibres. The stretching of the transversalis and tearing from the inguinal ligament account for the pain. The anatomical defects in the wall, i.e. the inguinal rings compound the problem (Figure 3). This theory accounts for both the common finding of adductor muscle pain and the presence of osteitis pubis. The injury is most likely to be an overuse syndrome. An alternative theory is that it is simply a chronic stretching of the posterior inguinal wall due to excess demands and aggravated by the anatomy of the region.

The differential diagnosis of groin pain is extensive. Snapping hip syndrome (Schaberg) with psoas bursitis as a cause of chronic, undiagnosed groin pain has been found on four occasions in the early series. It has been noted that the psoas tendon stretch can also produce pain in severe cases of sports hernia. There have been two cases of referred pain from spondylolisthesis of the fifth lumbar vertebra (L5). One was in a fast bowler who was treated successfully by fixation, and another in a runner which responded to local anaesthetic/steroid injection with no further pain at 3-months follow-up. Early osteoarthritis secondary to an old slipped upper femoral epiphysis was found in one martial arts exponent. Simple adductor strain or tendonitis has been the cause of two failures in this short series.

The use of herniography aided by computed tomographic scan and various manoeuvres to increase the sensitivity of the investigation is currently being studied in a prospective trial.

\section{Acknowledgements}

Thank you to those consultants who allowed me to treat their patients. 


\section{References}

1 Clement DB, Taunton JE, Smart GW. A survey of overuse running injuries. Phys Sportsmed 1981; 9: 47-58.

2 Gudas CJ. Patterns of lower limb extremity in 224 runners. Comp Ther 1980; 6: 50-9.

3 Renstrom P. Swedish research in sports traumatology. Chir Orthop 1984; 191: 144-58.

4 Muckle DS. Associated factors in recurrent groin and hamstring injuries. Br J Sports Med 1982; 16: 37-9.

5 Spinelli A. A new sports injury pubic pain in fencers. Orthopaedic Traumatologica dell' Apparato Motore 1932; 4: 111-27.

6 Bandini T. Notes on a syndrome of the recto-adductors in football players. Informatorio Medico 1948; 2: 295-7.

7 Schneider PG. Gracilis syndrome. Z Orthop 1963; 98: 43-50.

8 Gilmore G. Lecture to the London Sports Medicine Institute, 28 November 1990.

9 Blease S. Presentation to British Association of Sport and Medicine Congress, Groin Injuries Symposium, Samton Sands, UK, 1990.

10 Ekberg O, Persson N, Abrahamsson PA, Westlin EN, Lilja B Long-standing groin pain in athletes. Sports Med 1988; 6: 56-61.

11 Banks AJ, Malimson PD. Wrong diagnosis in athletes. $\mathrm{Br} J$ Sports Med 1982; 16: 101.

12 Taylor DC, Meyers WC, Moylan JA, Lohnes J, Bassett FH Garrett WE. Abdominal musculature abnormalities as a cause of groin pain in athletes. Am J Sports Med 1991; 3: 239-42.

13 Kirk Lyon E. Genitofemoral causalgia. Can Med Assoc J 1945; 53: 214-16.

14 Kopell H, Thompson WAL, Postel AH. Entrapment neuro- pathy of the ilio-inguinal nerve. $N$ Engl J Med 1962; 1: 16-19. 15 Smodlaka VN. Groin pain in soccer players. Phys Sportsmed 1980; 8: 57-61.

16 Horsky I, Huraj E. Surgical treatment of the painful groin Acta Chir Orthop Traumatol Cech 1984; 52: 350-3.

17 Hess $\mathrm{H}$. Inguinal pain: aetiology, differential diagnosis and therapy. Orthopadie 1980; 9: 186-9.

18 Hess $H$, Huberty $R$. Soccer injuries. In: Schneider RC, Kennedy JC, Plant M, eds, Sports Injuries. Mechanisms Prevention and Treatment. Baltimore, USA: Williams and Wilkins, 1985: 163-77.

19 Schneider PG. Inguinal pain: surgical therapy. Orthopadie 1980; 9: 190-2.

20 Martens M. Lecturer, Pees-en Spierletsels Big Sport, Brucosport Meeting, Brugge, October, 1991.

21 Cochrane GM. Osteitis pubis in athletes. Br J Sports med 1971; 5: 233-5.

22 Harris NH, Murray RO. Lesions of the symphysis in athletes. Br Med J 1974; 4: 211-14.

23 Le Jeune JJ, Rochcongar P, Vazelle F, Bernard AM, Herry JY, Ramee A. Pubic pain syndrome in sportsmen: comparison of radiographic and scintigraphic findings. Eur J Nucl Med 1984; 9: $250-3$.

24 Hanson $\mathrm{P}$, Angerine M, Juhl J. Osteitis pubis in sports activities. Phys Sportsmed 1978; 10: 111-14.

25 Gullmo A. Herniography, diagnosis of hernia in the groin and incompetence of the pouch of Douglas and pelvic floor. Acta Radiol Suppl (Stockh) 361: 229-43.

26 Williams JGP. Limitation of hip joint movement as a factor in traumatic osteitis pubis. Br I Sports Med 1978; 12: 129-33.

27 Bowerman JW. Radiology and Injury in Sport. New York, USA: Appleton-Century-Crofts, 1977: 241-5. 